\title{
The Relationship between Repeated Sprint Performance and Velocity Values during Loaded-Squat Jump Exercise
}

\author{
Ibrahim Can ${ }^{1}$, Seda Sadik $^{2}$ \& Serdar Bayrakdaroglu ${ }^{1}$ \\ ${ }^{1}$ School of Physical Education and Sports, Gumushane University, Gumushane, Turkey \\ ${ }^{2}$ School of Physical Education and Sports, Ordu University, Ordu, Turkey \\ Correspondence: Ibrahim Can, School of Physical Education and Sports, Gumushane University, Gumushane, \\ Turkey. E-mail: ibrahimcan@gumushane.edu.tr
}

\author{
Received: January 12, 2018 Accepted: January 25, $2018 \quad$ Online Published: February 5, 2018 \\ doi: $10.5539 /$ jel.v7n2p280 \\ URL: http://doi.org/10.5539/jel.v7n2p280
}

This study is presented as oral presentation in the "4th International Sport Science Tourism and Recration Student Congress" 'which was hosted by the Mehmet Akif Ersoy University in Turkey, 21 to 23th April 2017.

\begin{abstract}
The purpose of this study is to investigate the relationship between repeated sprint performance and velocity values during loaded-squat jump exercise. In accordance with this purpose, 23 kickboxing athletes (age: $21,1 \pm$ 2,10 years; height: $178,7 \pm 5,01 \mathrm{~cm}$; weight: 70,8 $\pm 7,85 \mathrm{~kg}$ ) participated voluntarily in this study. Participants were performed to repeated sprint test and loaded-squat jump exercise by using an external load corresponding to $40 \%$ of their body weight and velocity parameters were obtained as mean velocity (MV), mean propulsive velocity (MPV) and peak velocity (PV). Descriptive statistics were used in analysis of data. In addition, Spearman Correlation Analysis was used to determine the relationship between repeated sprint performance and velocity values during loaded-squat jump exercise. According to the analysis results; while total running times and fatigue index values in repeated sprint test of subjects were obtained as $52.4( \pm 1.96 \mathrm{sec})$ and $4.98( \pm 2.36 \%)$ respectively; velocity values during loaded-squat jump exercise were obtained as $1.38\left( \pm, 07 \mathrm{~m} / \mathrm{s}^{-1}\right)$ for $\mathrm{MP}, 1.54$ $\left( \pm, 10 \mathrm{~m} / \mathrm{s}^{-1}\right)$ for MPV, and $2.58\left( \pm, 15 \mathrm{~m} / \mathrm{s}^{-1}\right)$ for PV. In addition, it was determined that there was no any statistically significant difference between MP $(r=-, 148 ; r=-, 072, p>0.05$, respectively), MPV $(r=-, 335 ; r=$ - ,150, $\mathrm{p}>0.05$, respectively), PV ( $\mathrm{r}=, 010 ; \mathrm{r}=-, 034, \mathrm{p}>0.05$ respectively) and total running time and fatigue index values in repeated sprint test. As a result, it can be suggested that velocity values during loaded squat jump exercise have no statistically significant effect on repeated sprint performance.
\end{abstract}

Keywords: squat jump, velocity, repeated sprint

\section{Introduction}

Squat jumping is an exercise commonly used in testing lower-body muscle strength and showing rapidly acceleration competency of the body from a resting position which is important in workout and many branches of sports (Samozino et al., 2008). In addition, squat jumping exercise is also applied in order to evaluate an individual's strength competency performed by using different external loads (Garcia-Ramos et al., 2016; Jimenez-Reyes et al., 2017) and it is generally applied by using both a free-weight barbell and smith machine (Jimenez-Reyes et al., 2017; Stone et al., 2003). As known in physical science, jumping height is directly related to take-off velocity and many authors assess take-off velocity in order to determine vertical jumping performance (Luhtanen \& Komi, 1978; Kollias et al., 2001; Moir et al., 2008). Take-off velocity is an unchanging feature even when the individual jumps from the ground (Reiser et al., 2006) and it is closely related to maximal velocity. Therefore, it is thought that vertical jumping competency is directly related to maximal velocity (Gonzales-Badillo \& Marques, 2010) and especially when a vertical jumping is performed, maximal velocity is the best indicator to show vertical jumping performance due to the fact that maximal velocity determines the jumping height and it cannot be manipulated by the individual performing the move willingly or unwillingly (Gonzales-Badillo et al., 2017).

Velocity which is a vector quantity is stated as temporal rate of the changes in the positions (Zatsiorsky, 1998). The velocity of a muscle in the event of concentric contraction is inversely correlated to the applied external load 
or resistance. When the applied force is zero, the contraction velocity in the muscle is in its highest level. When the force equal to maximal force that will constrain the muscle increases, contraction velocity will be zero (Bartlett, 2007); that is as the lifted weight or load increases, the force generated by the muscle increases, but the movement velocity decreases. This situation is also correct empirically. If an athlete is asked to perform bench press in maximal weight, she or he will move the weight barbell in very slowly. However, when she/he is asked to perform the same exercise in the half of one repetition maximal (1RM), she or he will move the weight barbell in a faster way (Kraemer \& Vinger, 2007). It is specified that each $5 \%$ of increase in relative load (1RM\%) leads to difference between 0.07 and $0.09 \mathrm{~m} \cdot \mathrm{s}^{-1}$ and therefore, movement velocity is a variable that can attract more interest in order to follow up exercise intensity. The actual velocity in each repetition may be the best reference for the actual effort amount applied by the athlete (Gonzales-Badillo \& Sanchez-Medina, 2010).

Short sprints applied with short recovery periods are important in many sports branches. Thus, recovery ability among the sprints and renewal of the performance for the following sprints are the significant convenience determining the competency of repeatedly performing maximal or almost maximal efforts interspersed among short recovery periods (full resting or medium and low intensity activities) within expanded time period for the athletes in many sports branches and this is called repeated sprint ability (Bangsbo et al., 1991; Fitzsimons et al., 1993). When considered physiologically, repeated sprint ability is a complex feature which is believed to be related to both nerve-muscle (determination of maximal sprint speed such as neural stimulation or motor unit activation) and metabolic-related factors (such as oxidative capacity for creatine phosphate replacement) (Glaister, 2005; Spencer et al., 2005). In literature, there is not any study examining the relationship between repeated sprint performance and velocity parameters reached in loaded squat jump exercise measured by using a linear velocity transducer. Therefore, the purpose of the present study is examining the relationship between times in repeated sprint test and velocity values during loaded squat jump exercise of kickboxing athletes.

\section{Method}

23 kickboxing athletes (age: 21,1 $\pm 2,10$ years; height: 178,7 $\pm 5,01 \mathrm{~cm}$; body weight: 70,8 $\pm 7,85 \mathrm{~kg}$ ) participated the study voluntarily. A 769-branded electronic measuring tool (Seca Corporation, Hamburg, Germany) which possesses $0.001 \mathrm{~m}$ and $0.01 \mathrm{~kg}$ accuracy respectively was used in acquiring height and body weight measures of the subjects. After determining physical features of the subjects, load values corresponding to $40 \%$ of their body weight was calculated. After giving detailed information about the applied test procedure, the subjects were exposed to a 20-minute warm-up activity composing of 15 -minute of general warm-up (5 minutes for stretching the lower-body and 10 minutes for running) and 5-minute of special exercise (squat practices in sub-maximal level). After warm-up activities, the subjects were exposed to loaded squat jump test by using external loads corresponding to $40 \%$ of their body weight. In applying test protocols, the subjects were asked to bring their knees in flexion from a static position until their thighs became parallel to the ground and to jump as fast as possible without losing their shoulder contact with the barbell after the command and to repeat that practice three times (Loturco et al., 2015). The practice was repeated when the specified test rules were not followed; because in addition to the external load used in the application of the test, it was needed to move body weight and by that means, kinetic-kinematic parameters such as velocity and power were determined with the individual's acceleration competency of total mass comprising external load and body weight (Cormie et al., 2007). A linear velocity transducer (T-Force Dynamic Measurement System; Ergotech Consulting S.L, Murcia, Spain) was connected to the end of a free-weight barbell in order to determine velocity and power parameters. The use of this system is suitable for any resistance workout exercise in which it is compulsory to overcome a moving load (constant mass) through a vertical axis against gravity or especially for a typical weight-lifting exercise. The system includes electromechanical equipment (velocity sensor and interface), a special computer program managing this equipment (T-Force system software) and a hook connected to the weight workout barbell (Sanchez-Medina et al., 2010).

Repeated sprint ability (RSA) of the subjects was tested by using repeated sprint test which was designed by Bangsbo (1994), composed of 7 sprint runs performed with maximal speeds on 34.2 meter length area and which had 25 seconds of resting period after each running (Abrantes et al., 2004). Test area is given in figure 1. Before applying repeated sprint test, the subjects were informed about test procedures in detail and they were asked to perform 10-minute of run and 5-minute of warm-up exercises in low intensity as well as carrying out passive resting sprints so as to adjusting the subjects to the test procedures. Full resting was given for the subjects and repeated sprint test was applied twice by giving the sufficient resting time in order to get the best results in measurements and the best results were recorded for statistical analysis. Each sprint value was acquired by using a portable photocell (Newtest Powertimer, Model300s, Oy, Finland) replaced on the starting and finish point. Fatigue index (FI) values of the subjects were calculated according to the following formula (Oliver, 2009). 
Formula: \% FI $=(\mathrm{TT}-\mathrm{IT}) / \mathrm{IT} \times 100$

Ideal Time (IT): $\mathrm{B}_{\mathrm{TT}} \times 7$

Total Time (TT): $\mathrm{S} 1+\mathrm{S} 2+\mathrm{S} 3+\mathrm{S} 4+\mathrm{S} 5+\mathrm{S} 6+\mathrm{S} 7$

$\mathrm{B}_{\mathrm{TT}}$ : Best Testing Time

S: Sprint

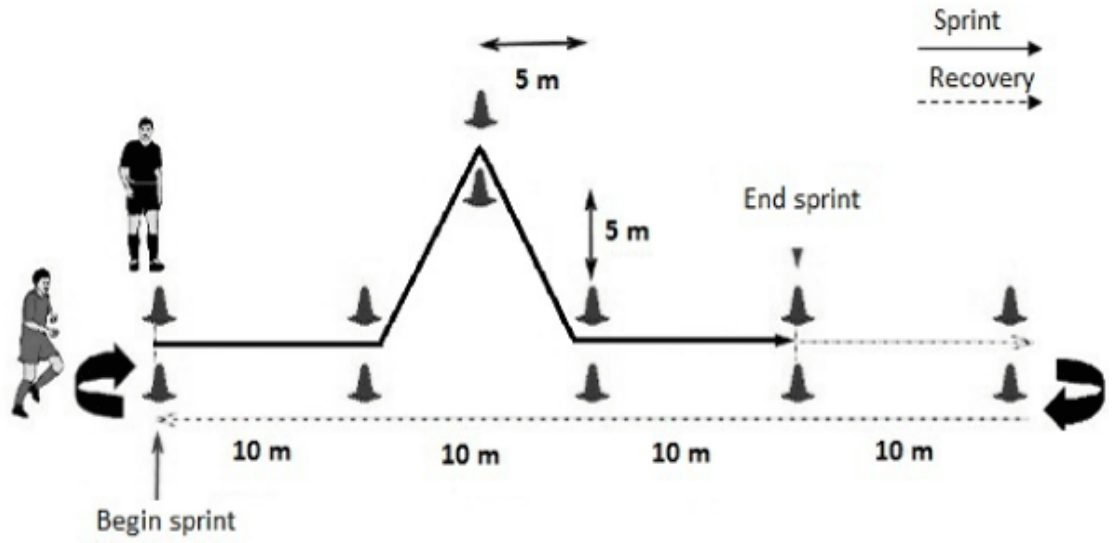

Figure 1. Repeated sprint test (Sporis et al., 2009)

In the analysis of data, descriptive statistics were used. Furthermore, Spearman Correlation Analysis was used in order to determine the relationship between velocity values in loaded squat jump exercise and repeated sprint performances of the subjects. SPSS 16.0 statistical package programme (SPSS Inc, Chicago, IL) was used for all statistical processes and significance level was accepted as $\mathrm{p}<.05$.

\section{Results}

Physical features of the subjects are given in table 1, running times in repeated sprint test are given in table 2 and descriptive statistical results showing velocity values which were acquired during concentric phase of loaded squat jump move applied by using free-weights with an external load corresponding to $40 \%$ of the subjects' body weights are given in table 3 .

Table 1. Physical characteristics of participants

\begin{tabular}{lllll}
\hline Variables & $\mathrm{n}$ & Minimal & Maximal & Mean (sd) \\
\hline Age (years) & 23 & 18,00 & 25,00 & $21,1( \pm 2.10)$ \\
Height $(\mathrm{cm})$ & 23 & 169,00 & 186,00 & $178,7( \pm 5.01)$ \\
Weight $(\mathrm{kg})$ & 23 & 60,30 & 87,00 & $70,8( \pm 7.85)$ \\
\hline
\end{tabular}

Table 2. Participant's repeated sprint test results

\begin{tabular}{lllll}
\hline Variables & $\mathrm{n}$ & Minimal & Maximal & Mean $(\mathrm{sd})$ \\
\hline RST1 (sec.) & 23 & 6,70 & 7,71 & $7,18( \pm, 23)$ \\
RST2 (sec) & 23 & 4,94 & 8,04 & $7,16( \pm, 57)$ \\
RST3 (sec) & 23 & 6,98 & 8,23 & $7,42( \pm, 35)$ \\
RST4 (sec) & 23 & 6,98 & 8,36 & $7,56( \pm, 34)$ \\
RST5 (sec) & 23 & 7,09 & 8,45 & $7,65( \pm, 35)$ \\
RST6 (sec) & 23 & 7,16 & 8,60 & $7,74( \pm, 38)$ \\
RST7 (sec) & 23 & 7,08 & 8,50 & $7,69( \pm, 32)$ \\
Fatigue Index (\%) & 23 & 1,63 & 9,42 & $4,98( \pm 2,36)$ \\
Total Time (sec) & 23 & 49,27 & 56,54 & $52,47( \pm 1,96)$ \\
\hline
\end{tabular}

Note. RST: Repeated Sprint Test. 
Table 3. Velocity values during loaded-squat jump exercise was performed by using an external load equivalent to the $40 \%$ of the body weights of the participants

\begin{tabular}{lllll}
\hline Variables & $\mathrm{n}$ & Minimal & Maximal & Mean $(\mathrm{sd})$ \\
\hline $\mathrm{MV}\left(\mathrm{m} / \mathrm{s}^{-1}\right)$ & 23 & 1,18 & 1,53 & $1,38( \pm, 07)$ \\
$\operatorname{MPV}\left(\mathrm{m} / \mathrm{s}^{-1}\right)$ & 23 & 1,23 & 1,72 & $1,54( \pm, 10)$ \\
$\operatorname{PV~}\left(\mathrm{m} / \mathrm{s}^{-1}\right)$ & 23 & 2,17 & 2,80 & $2,58( \pm, 15)$ \\
\hline
\end{tabular}

Note. MV: Mean Velocity; MPV: Mean Propulsive Velocity; PV: Peak Power.

Correlation analysis results showing the relationship between running times in repeated sprint test and velocity values reached in concentric phase of loaded squat jump exercise are shown in table 4. According to analysis results, there is not a statistically significant relationship between running times in repeated sprint test and velocity values acquired in concentric phase of loaded squat jump applied by using free weights with external weight corresponding to $40 \%$ of the athletes' body weight ( $p>0.05$ ).

Table 4. Spearman correlation anaylsis results between repeated sprint test performance and velocity values during loaded-squat jump exercise

\begin{tabular}{|c|c|c|c|c|c|c|c|c|c|c|}
\hline & & RST1 & RST2 & RST3 & RST4 & RST5 & RST6 & RST7 & FI & TT \\
\hline \multirow[t]{3}{*}{ MV } & Correlation Coefficient &,- 167 &,- 185 &,- 229 &,- 242 &,- 241 &,- 087 &,- 171 &,- 072 &,- 148 \\
\hline & Sig. (2-tailed) & ,446 & ,397 & ,293 & ,265 & ,269 & 695 &, 435 & ,744 &, 500 \\
\hline & $\mathrm{n}$ & 23 & 23 & 23 & 23 & 23 & 23 & 23 & 23 & 23 \\
\hline \multirow[t]{3}{*}{ MPV } & Correlation Coefficient &,- 219 &,- 325 &,- 400 &,- 443 &,- 409 &,- 206 &,- 332 &,- 150 &,- 335 \\
\hline & Sig. (2-tailed) &, 315 &, 131 &, 058 & ,034* & 053 & ,346 &, 122 & ,494 &, 119 \\
\hline & $\mathrm{n}$ & 23 & 23 & 23 & 23 & 23 & 23 & 23 & 23 & 23 \\
\hline \multirow[t]{3}{*}{ PV } & Correlation Coefficient &, 019 &,- 037 &,- 142 &,- 206 &,- 121 &,- 011 &,- 059 &,- 034 & 010 \\
\hline & Sig. (2-tailed) & ,932 &, 867 &, 519 &, 347 &, 584 & ,959 & ,788 & ,879 & ,964 \\
\hline & $\mathrm{n}$ & 23 & 23 & 23 & 23 & 23 & 23 & 23 & 23 & 23 \\
\hline
\end{tabular}

Note. * P<0.05; MV: Mean Velocity; MPV: Mean Propulsive Velocity; PV: Peak Power; RST: Repeated Sprint Test; FI: Fatigue Index; TT: Total Time.

\section{Discussion}

The purpose of this study is examining the relationship between running times in repeated sprint test and velocity values during loaded squat jump exercise of kickboxing athletes. In literature, there is not any study examining the relationship between repeated sprint performance and velocity parameters reached in concentric phase of loaded squat jump exercise measured by using a linear velocity transducer. In literature, there are studies examining the present relationship between short sprint times and velocity values acquired during jumping exercises (Marques et al., 2009, 2011) of amateur athletes competing in different branches or reached in concentric phase of full squat exercise applied in different loads (Can, 2014). Thus, it is thought that the results acquired from this study conducted on kickboxing athletes are important for the literature of sports science and this study will be reference source for the studies to be conducted in the future.

In a study conducted by Can (2014), it was found that there was a medium level, negative and statistically significant relationship between 30 meter sprint times and the peak velocity values reached in $40 \%$ and $60 \%$ loads, mean velocity values reached during concentric phase of a full back squat movement performed $20 \%$ and $90 \%$ of one repetition maximal; on the other hand it was found that there was no significant relationship between 5 -meter sprint times and velocity parameters in the propulsive phase of full back squat movement applied in different loads. In a study carried out by Marques et al. (2011) on amateur athletes in different branches (football, futsal and handball), it was found that there was no significant relationship between 5-meter sprint times and mean propulsive velocity and peak velocity values during countermovement jumping exercise. In another study conducted by Marques et al. (2009) on track and field athletes, it was stated that there was a significant correlation between short sprint performance and squat jumping. Similarly, Nagahara et al. (2014) reported that squat jumping height was related to 60 -meter sprint time. Besides, in the conducted studies, it was found that some vertical jumping variables were related to sprint performance (Nesser et al., 1996; Dowson et al., 1998; 
Wisloff et al., 2004; Lopez-Segovia et al., 2011) and it was asserted that decrease in jumping ability was a good indicator of nerve-muscle fatigue stemming from high-intensity repeated efforts (Gorostiaga et al., 2010; Sanchez-Medina \& Gonzales-Badillo, 2011). In this study, it was found that there was no significant relationship between repeated sprint performance and mean velocity, mean propulsive velocity and peak velocity values during loaded squat jump exercise applied with external loads corresponding to $40 \%$ of the athletes' body weight by using free weights. Consequently, it can be asserted that statistically the absence of a significant relationship may stem from the fact that firstly, repeated sprint in kickboxing is not a ability needing to be developed and it is not included in training program.

\section{References}

Abrantes, C., Macas, V., \& Sampaio, J. (2004). Variation in Football Players's Sprint Test Performance across Different Ages and Levels Competition. Journal of Sports Science and Medicine, 3(1), 44-49.

Bangsbo, J. (1994). Fitness Training for Football: A Scientific Approach. Bagsverd. HO+Storm.

Bangsbo, J., Norregaard, L., \& Thorso, F. (1991). Activity Profile of Competition Soccer. Canadian Journal of Sport Science, 16(2), 110-116.

Bartlett, R. (2007). Introduction to Sports Biomechanics: Analysing Human Movement Patterns. Oxon: Routledge.

Can, İ. (2014). The Relationship with Sprint and Jump Performances of Kinetics-Kinematics in the Propulsive Phase of Full Squat Movement. Karadeniz Technical University, Institute of Educational Sciences (Doctoral Thesis), Trabzon.

Cormie, P., McCaulley, G. O., Triplett, N. T., \& McBride, J. M. (2007). Optimal Loadig for Maximal Power Output during Lower Body Resistance Exercises. Medicine and Science in Sports and Exercise, 39(2), 340-349. https://doi.org/10.1249/01.mss.0000246993.71599.bf

Dowson, M. N., Nevil, M. E., Lakomy, A. M., Nevil, A. M., \& Hazeldine, R. J. (1998). Modeling the Relationship between İsokinetic Muscle Strength and Sprint Running Performance. Journal of Sport Sciences, 16(3), 257-265. https://doi.org/10.1080/026404198366786

Fitzsimons, M., Dawson, B., Ward, D., \& Wilkinson, A. (1993). Cycling and Running Tests of Repeated Sprint Ability. Australian Journal of Science and Medicine Sport, 25(4), 82-87.

Garcia-Ramos, A., Stirn, I., Padial, P., Argüelles-Cienfuegos, J., De La Fuente, B., Calderon, C., ... Feriche, B. (2016). The Effect of An Altitude Training Camp on Swimming Start Time and Loaded Squat Jump Performance. PLoS One, 11(7), 1-11. https://doi.org/10.1371/journal.pone.0160401

Glaister, M. (2005). Multiple Sprint Work: Physiological Responses, Mechanisms of Fatigue and the Influence of Aerobic Fitness. Sports Medicine, 35(9), 757-777. https://doi.org/0112-1642/05/0009-0757/\$34.95/0

Gonzales-Badillo, J. J., \& Marques, M. C. (2010). Relationship between Kinematic Factors and Countermovement Jump Height in Trained Track and Field Athletes. Journal of Strength and Conditioning Research, 24(12), 3443-3447. https://doi.org/10.1519/JSC.0b013e3181bac37d

Gonzales-Badillo, J. J., \& Sanchez-Medina, L. (2010). Movement Velocity as A Measure of Loading Intensity in Resistance Training. International Journal of Sports Medicine, 31(5), 347-352. https://doi.org/10.1055/s-0030-1248333

Gonzales-Badillo, J. J., Jimenes-Reyes, P., \& Ramirez-Lechuga, J. (2017). Determinant Factors of the Squat Jump in Sprinting and Jumping Athletes. Journal of Human Kinetics, 15, 15-22. https://doi.org/10.1515/hukin-2017-0067

Gorostiaga, E. M., Asiáin, X., Izquierdo, M., Postigo, A., Aguado, R., Alonso, J. M., \& Ibáñez, J. (2010). Vertical Jump Performance and Blood Ammonia and Lactate Levels During Typical Training Sessions in Elite 400m Runners. Journal of Strength and Conditioning Research, 24(4), 1138-1149. https://doi.org/10.1519/JSC.0b013e3181cf769f

Jimenez-Reyes, P., Samozino, P., Brughelli, M., \& Morin, J. B. (2017). Effectiveness of An Individualized Training Based on Force-Velocity Profiling During Jumping. Frontiers in Physiology, 7, 1-13. https://doi.org/10.3389/fphys.2016.00677

Jimenez-Reyes, P., Samozino, P., Pareja-Blanco, F., Conceicao, F., Cuadrado-Penafiel, V., Gonzalez-Badillo, J. J., \& Morin J. B. (2017). Validity of A Simple Method for Measuring Force-Velocity-Power Profile in 
Countermovement Jump. International Journal of Sport Physiology and Performance, 12(1), 36, 43. https://doi.org/10.1123/ijspp.2015-0484

Kollias, I., Hatzitaki, V., Papaiakovou, G., \& Giatsis, G. (2001). Using Principal Components Analysis to Identify Individual Differences in Vertical Jump Performance. Research Quarterly for Exercise and Sport, 72(1), 63-67 https://doi.org/10.1080/02701367.2001.10608933

Kraemer, J. W., \& Vinger, L. J. (2007). Muscle anatomy. In E. L. Brown (Eds.), Strength training: National strength and conditioning association (pp. 3-28). Champaign, IL: Human Kinetics.

Lopez-Segovia, M., Marques, M. C., Van Der Tillar, R., \& Gonzales-Badillo, J. J. (2011). Relationship between Vertical Jump and Full Squat Power Outputs with Sprint Times in U21 Soccer Players. Journal of Human Kinetics, 30, 135-144. https://doi.org/10.2478/v10078-011-0081-2

Loturco, I., D’Angelo, R. A., Fernandes, V., Gil, S., Kobal, R., Cal Abad, C. C., ... Nakamura, F. Y. (2015). Relationship between Sprint Ability and Loaded / Unloaded Jump Tests in Elite Sprinters. Journal of Strength and Conditioning Research, 29(3), 758-764. https://doi.org/10.1519/JSC.0000000000000660

Luhtanen, P., \& Komi, R. V. (1978). Segmental Contribution to Forces in Vertical Jump. European Journal of Applied Physiology and Occupational Physiology, 38(3), 181-188. https://doi.org/10.1007/BF00430076

Marques, M. C., Gil, H., Ramos, R., Costa, A. M., \& Marinho, D. A. (2011). Relationship Between Vertical Jump Strength Metrics and 5 Meters Sprint Times. Journal of Human Kinetics, 29, 115-122. https://doi.org/10.2478/v10078-011-0045-6

Marques, M. C., Silva-Dias, P., Marinho, D. A., \& Gonzalez-Badillo, J. J. (2009). The Relationships between Squat Jump and Short Sprint Performance in Trained Track and Field Athletes. Journal of Sports Science and Medicine, 8(S11), 120. https://doi.org/10.2478/v10078-011-0081-2

Moir, G., Shastri, P., \& Connaboy, C. (2008). Intersession Reliability of Vertical Jump Height in Women and Men. Journal of Strength and Conditioning Research, 22(6), 1779-1784. https://doi.org/10.1519/JSC.0b013e318185f0df

Nagahara, R., Naito, H., Miyashiro, K., Morin, J. B., \& Zushi, K. (2014). Traditional and Ankle-Specific Vertical Jumps as Strength-Power Indicators for Maximal Sprint Acceleration. Journal of Sports Medicine and Physical Fitness, 54(6), 691-699.

Nesser, T. W., Latin, R. W., Berg, K., \& Prentice, E. (1996). Physiological Determinants of 40-Meter Sprint Performance in Young Male Athletes. Journal of Strength and Conditioning Research, 10, 263-267. https://doi.org/10.1519/00124278-199611000-00010

Oliver, J. L. (2009). Is A Fatigue Index A Worthwhile Measure of Repeated Sprint Ability. Journal of Science and Medicine in Sport, 12(1), 20-23. https://doi.org/10.1016/j.jsams.2007.10.010

Reiser, R. F., Rocheford, E. C., \& Armstrong, C. J. (2006). Building A Better Understanding of Basic Mechanical Principles Through Analysis of the Vertical Jump. Strength and Conditioning Journal, 28, 70-80. https://doi.org/10.1519/00126548-200608000-00012

Samozino, P., Morin, J. B., Hintzy, F., \& Belli, A. (2008). A Simple Method for Measuring Force, Velocity and Power Output during Squat Jump. Journal Biomechanics, Biomech, 41(14), 2940-2945. https://doi.org/10.1016/j.jbiomech.2008.07.028

Sanchez-Medina, L., \& Gonzales-Badillo, J. J. (2011). Velocity Loss as an Indicator of Neuromuscular Fatigue During Resistance Training. Medicine and Science in Sports and Exercise, 43(9), 1725-1734. https://doi.org/10.1249/MSS.0b013e318213f880

Sanchez-Medina, L., Perez, C. E., \& Gonzales-Badillo, J. J. (2010). Importance of the Propulsive Phase in Strength Assessment. International Journal of Sports Medicine, 31(2), 123-129, 2010. https://doi.org/10.1055/s-0029-1242815

Spencer, M., Bishop, D., Dawson, B., \& Goodman, C. (2005). Physiological and Metabolic Responses of Repeated Sprint Activities: Specific to Field - Based Team Sports. Sports Medicine, 35(12), 1025-1044. https://doi.org/0112-1642/05/0012-1025/\$34.95/0

Sporis, G., Milanovic, Z., Trajkovic, N., Erceg, M., \& Novak, D. (2012). Relationship Between Functional Capacities and Performance Parameters in Soccer. Journal of Sports Medicine and Doping Studies, 1-5. http://dx.doi.org/10.4172/2161-0673.S2-001 
Stone, M. H., O’Bryant, H. S., McCoy, L., Coglianese, R., Lehmkuhl, M., \& Schilling, B. (2003). Power and Maximum Strength Relationships during Performance of Dynamic and Static Weighted Jumps. Journal of Strength and Conditioning Reserch, 17(1), 140-147.

Wisloff, U., Castagna, C., Helgerud, J., Jones, R., \& Hoff, J. (2004). Strong Correlation of Maximal Squat Strength with Sprint Performance and Vertical Jump Height in Elite Soccer Players. British Journal of Sports Medicine, 38(3), 285-288. https://doi.org/10.1136/bjsm.2002.002071

Zatsiorsky, V. M. (1998). Kinematics of Human Motion. Champaign, IL: Human Kinetics.

\section{Copyrights}

Copyright for this article is retained by the author(s), with first publication rights granted to the journal.

This is an open-access article distributed under the terms and conditions of the Creative Commons Attribution license (http://creativecommons.org/licenses/by/4.0/). 